\title{
Unlearning Architecture(s)
}

IVAN DELGADO

Universidad Veritas

Much of an architect's training occurs by a process of elimination. We must unlearn many things to learn the new ones; in our particular Costa Rican educational context learning to produce correct architecture seems to start with the assumption that most of what we see in our cities is wrong. But when it comes to construction we move between two traditions: the academic one and the informal one. These traditions seem to dismiss each other, an architect would consider the products of informality ingenuous, a person operating within the informal tradition in need of the materialization of the preconceived idea of a house would normally consider an architect a luxury. According to the National Architectural College $23 \%$ of overall construction lacked permits in 2014, a percentage slightly higher than the previous year, this nevertheless renders only partial understanding on the phenomenon.

Which of the two traditions accounts for the majority of what is built in this country ? What significant informal knowledge percolates to the present after a much longer presence than formal education and how is it transmitted ? What role does representation play in the informal tradition ? are instructions drawn or narrated ?... How do architects unlearn what they do not understand in full ?

A house designed by the author in the rural North of Costa Rica functions as a catalyst for further investigation on how the upbringing of an architect collides with more traditional ways of building. In a village where no other architect has practiced before the author discovers several categories of construction, from the temporary huts vendors use to sell fruits and milking parlors, to houses that have been built following traditional "recipes". The house learns lessons of practicality from these structures and is informed by their aesthetics. It also employs the old "vara" $(0.84 \mathrm{~m})$ as the unit of measurement in an attempt to make itself communicable to local builders. In practice, due to the lack of skill for reading formal construction drawings, the instructions to build the house end up being narrated rather than read.

This paper will study informal construction in Costa Rica which is symptomatic of Latin America in general particularly in rurality where it occurs the most. It will collect information from specific cases on how decisions where made and how they were transmitted, and will look for ways to hierarchize them in order to identify which are part of a basic set of instructions (or recipe, meaning there can be small creative variations of the ingredients) and which take place as more significant deviations from those instructions. It will also propose ways to convey the graphic implications of this information that is compatible with the inflections that occur in the orality of these particular context, and finally it will put forward a discussion on ways for an architect to learn from and operate within it, anticipating that our built environment takes shape as a trade-off between both traditions.

A HOUSE FOR A FRIEND OF THE FAMILY

"A friend asked us to design a house with her retirements savings which amounted to $\$ 42000$ in the village of La Vega in the North of Costa Rica. It was evident that no other architect had built anything there before. It did not feel like we were going to teach anybody anything but the other way around. We learned lessons of practicality from the traditional structures, we used the old vara $(84 \mathrm{~cm})$ as the unit of measurement within a regular layout and employed 


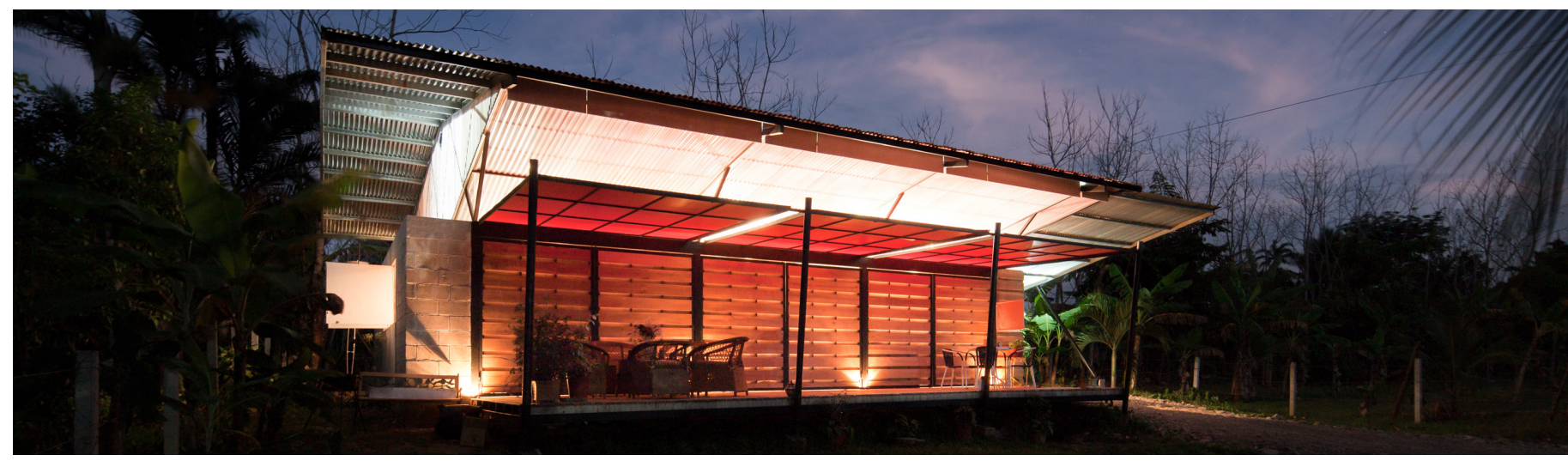

Figure 1: A house designed in La Vega, Costa Rica, a village where no other architect had practiced before.

recognizable shapes to make it communicable. A small model ended up being used more than the drawings we produced.

In the end however it felt more like a formal response with an expected spatial outcome than the result of a deep understanding of a tradition.

The timeframe for a design is very short and we were left with the feeling that one is scratching the surface of something bigger "

\section{FIELDWORK - FINDINGS}

For a period of four months a significant amount of visits to residences and interviews with their owners were accumulated. In all cases they were involved in the construction of their houses either directly with their own hands or by closely overseeing a small crew of workers. The conversations were in most cases induced by the space itself, and evolved from a basic set of questions which in all cases dealt with how the assignments were communicated, what were considered necessities and what solutions, and particularly how negotiations took place between what was required and what was offered. It was also important to understand the antecedents of the identification of the need for the house in their temporal and physical context, which is rural in every case. A separate interview with a scholar was necessary to delimit a more generalized situation.

The next sections will show 3 cases that summarize a series of recurrent phenomena that have been identified during the interviews. These situations evolve from the understanding of decissions on the siting of the houses, the responsibility for changes during construction and the type of language used to convey knowledge and instructions in general, among others. The cases are placed in a range between the furthest from and the closest to a limited definition of informality: -that which is not subject to the regulation of institutionsthis means that the act of construction is not oficially registered and that the persons involved have not received a formal training.

Aditionally, given that no evidence of written or graphic records of these processes has been found, I will propose to convey the graphic implications of these findings in an attempt to mediate between orality and formality. Axonometric projection is adopted, understanding its long lineage of use as both measurable and symbolic. The early 20th century avant-garde artists are of particular interest, who used axonometric's atopical space and reversibility that does not freeze space and motion as does perspective, but provides and ambiguous spatial field where elements are in constant motion (1). This is compatible with the climate of temporal vagueness that prevails in rural Costa Rica and reflected in the inflections of language, the use of words and verb tenses found recurrently in the research that communicate a general sense of expectation and indeterminacy. Also, the possibility of reading elevations and plans simultaneously is consistent with the way the houses are drawn by the people involved in their construction (when required by the author); although this is not exclusive of this context, it reveals that these aspects are considered continuous and inseparable.

\section{CASA PACHUCA - AN INTERVIEW WITH ANDRES FERNANDEZ-}

Andrés Fernandez has spent the last 25 years studying the city of San Jose making use of instruments provided by sociology, psychology and ethnology in order to understand its Architecture, and in so doing has extended his research to the rest of the small Costa Rican territory which has undoubtedly informed its capital and largest city. During the course of this research outside San Jose, Fernandez has come across "unclassifiable" pieces of Architecture, according to him mainly because of their aesthetic heterodoxy or their constructional eclecticism.

One particular case is the casa Pachuca, a ubiquitous type of house that appeared in the early 1960's. It could be said that it is so common it has become invisible, to the point that it is difficult for the general citizen to name it as distinct type of house. In fact labeling the house "pachuca" (in Costa Rica slang, informal language) implies making a clear distinction between the "pure or formal" and the informal from an academic stance. Given its widespread presence this case is not substantiated by a single residence but by a collection of general features as described by Fernandez.

The reason why the pachucas are considered a deviation from a norm is that they are the result of adaptations after a transmission of knowledge from one generation to the next: the first modernist architects working in San Jose in the 1950's trained builders, particularly carpenters, but they were not interested in working outside the city or to design small houses, this void was filled by the builders. The 


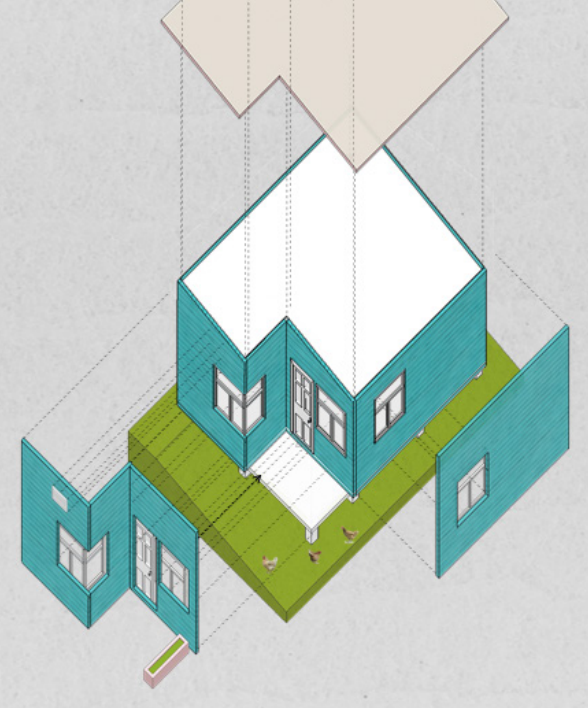

Figure 2: Casa Pachuca, a typical configuration.

knowledge was entirely practical and segmented, not theoretical, which resulted in houses as an assemblage of a very defined repertoire of components when the builders moved out of San Jose to "make modern houses" for a more rural clientele. The background of the builders and that of the owners added to the vocabulary with new components such as planters, serrated roofs that evolved from the already tropicalized roofs of the local modernists, corridors, and particularly color; familiar components of a house -those that can be named-are preferred to the abstraction architects produced when they adhered to Modernism. The act of building is a result in itself, design is not a prerequisite and does not happen in academic terms, but is inherently contained in the decisions needed to distribute the components in practical circumstances, for instance, using adapted overhangs where the sun or rain hit, louvers facing prevailing winds or elongated windows where there is a view. Drawings are not employed, not even to record these practical decisions, this eliminates the possibility of drawing an etymological connection to design. The results are, again, a dosage and arrangement of more or less the same ingredients as the response to direct knowledge of a site and of the human body as the unit of measure and the gestural reference for the relative positions and dimensions of those components (this was attuned to the use of the vara $(0.84 \mathrm{~m}$.) and imperial units); the most distinctive characteristic is perhaps using the navel as the reference for most of what happens inside the house, the base for the walls happens at this height and consequently windowsills, besides countertops and doorknobs, among several others. Wood as the material par excellence was meticulously employed, there would be almost no waste, any surplus material would be used for decoration -in contrast with their modernist predecessors- and in consequence space benefitted from this optimization, any "surplus space" was used for storage or for domestic animals.

The procedure to build these houses can be described as a recipe, there is a categorical set of sequential oral instructions that covers most contextual physical circumstances. There is little room for improvisation but there is flexibility for adaptation to more unusual situations, noteworthy examples of casas pachucas have resulted from the adjustment to more dramatic topographies or climatic conditions. Over time particular mannerisms such as slanting columns and walls and corner windows emerge from repetitive minor changes that eventually become a builder's signature, a sort of protodesign occurs.

Casas Pachucas started to decline in the late 1970's, after the devaluation of trades in favor of academic training, the replacement of wood for exogenous materials and even the adoption of the metric system, which to this date is a reason for friction between the informal and the formal traditions.

\section{RECIPE AND IMPROVISATION - SAN ANTONIO, 1955 -}

A loan of $\$ 200$ is used to build a house in the mountainous outskirts of San Jose, for a mother and her 4 children in 1955 . The builder offered two options: the wraparound porch house and the simple "zaguan" (central hallway) house, a basic version of the latter fits the budget. At that time a site within a sizable piece of land would be chosen for its security against landslides or floods, earthwork was not possible. The house consists of two bedrooms flanked by the kitchen and living room at each end, the possibility of growth is priviledged over other criteria.

In many situations land was abundant and cheap and territorial markers such as infrastructure, vaguely defined abstract boundaries or other neighbors were not decisive in the configuration of the house. Rather, the geometry is restrictive from the perimeter inward, the self-imposed constraints respond to an order at the same time detached from nature and contained by it. This geometry is defined by a grid of $0.84 \mathrm{~m} \times 0.84 \mathrm{~m}$ ( 1 square vara) as the basic unit, that is projected over a moderate topography. The floor dimensions of bedrooms, the shower room and kitchen as well as the wall height of 3 varas $(2.52 \mathrm{~m})$ are predetermined and accepted by the owner and builder.

The four initial corners would be placed among trees and geographical circumstances, not aligned with anything in particular, frontality was not important but a recognizable facade was, a simple faceted roof accomplishes this. A familiar silhouette is desirable but the components contained by the frames are adjusted to very specific needs, windows and overhangs are adjusted constantly during construction and during the lifetime of the house.

The house is never finished, the expression "in the future" is inherent to it. The wood for the walls serves more practical purposes such as accumulating belongings, the utility of the floor taken to a vertical plane, its components, particularly the boards can be disassembled and reassembled easily, there is no pretension to a finished condition of 


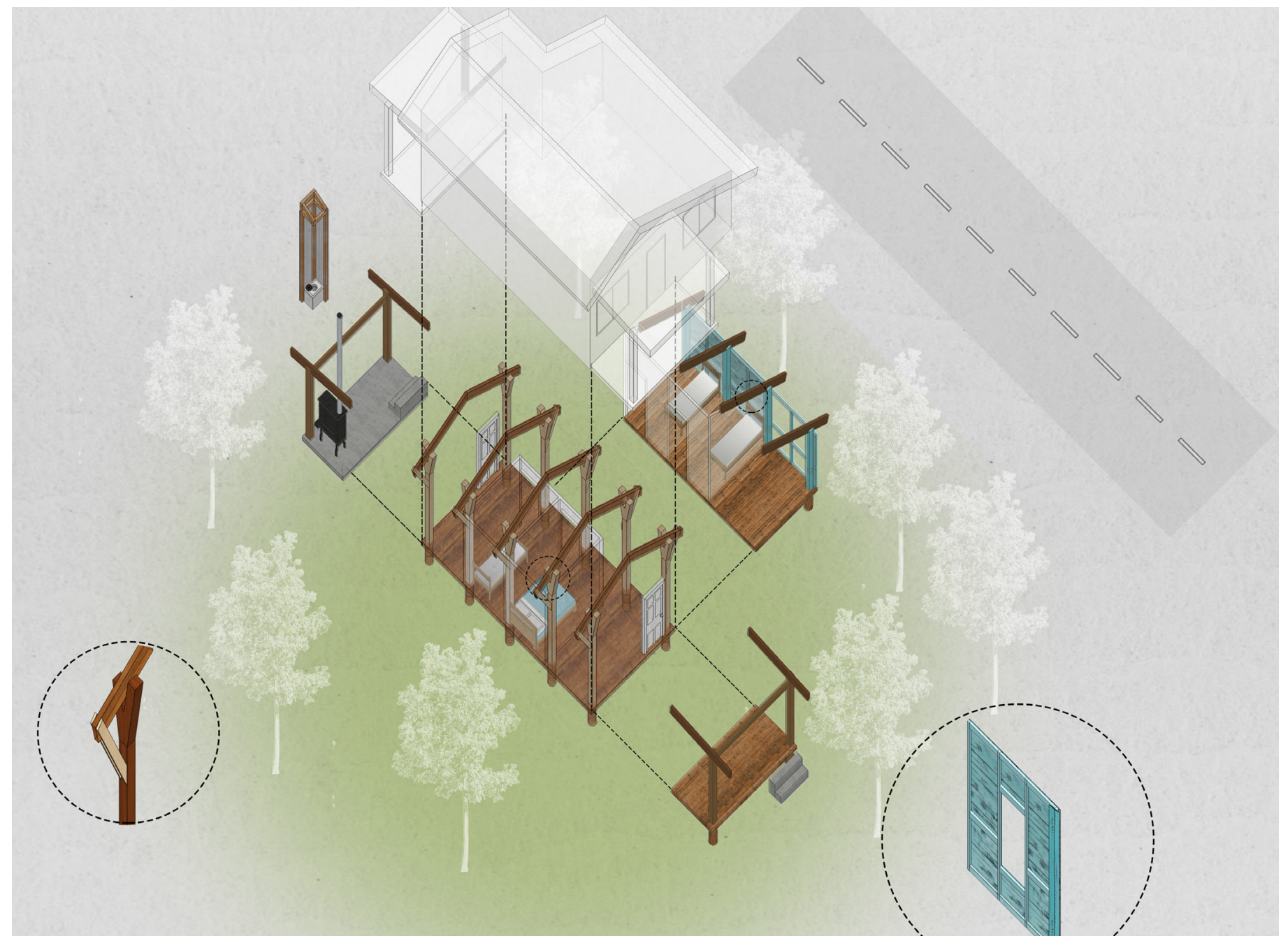

Figure 3: House in San Antonio

the wall. This is also evident in the disparity of the windows when seen from outside, the compositional ambition that comes with drawing as planning exercise is not there.

There is a recurrence in the use of words to describe building components that percolated from formal construction language and that have lost their meaning, some of which have even generated verbs, such as "cimbrar" which more or less means the vibration and sound caused by an impact on a roof, derived from "cimbra" which means formwork and not rafter which would be a closer present-day definition. These words all denote a provisional status as if they are meant to be replaced just as the house is to be altered, they have been adapted to the expectant tone of oral communication in Costa Rican rurality.

\section{FIRSTHAND KNOWLEDGE - PURISCAL, 2010 -}

According to Henri Lefebvre's triple dialectic of space (3), a space of representation is where alternatives for the re structuring of the institutionalized representations of space occur.

It is inevitable to see a resemblance to this in this case in that there is a re-use of a vacant space, a leftover of the market system right next to a national highway by-passing the representation of space but through a direct emphatic action on the land by means of a grid that starts at the most prominent point on the lot. This point is chosen through a direct relationship with the terrain, not only with its topography but also its environmental and scenic characteristics; representation as a reduction or synthesis of those circumstances is not employed, in fact, a contour map, for instance, would be unintelligible to the builder.

The grid is in accordance to the dimensions of discarded electric poles and beams. The structure is the result of what can be built by 2 persons with 5 tools and what can be described with words and with the hands. This results in a functional space, a retail store that happens at ground level and is projected over a steep downward slope, the remaining room between the floor and the cliff is the living space, as the poles are extended downward to reach stable ground, thus this space is a consequence and not an end. A proof of this is that the house is entered through the bedrooms directly and concludes in what may be called the living room; there are no hallways and consequently no social space as such, in that every space is open to socialization. In the words of the owner it is a place for priorities and not for exposure. It is tempting again to see an analogy with the distortion of the official conceived space according to Lefebvre here, a place for "disobedience", as it is difficult for an architect to label the parts of this house. 


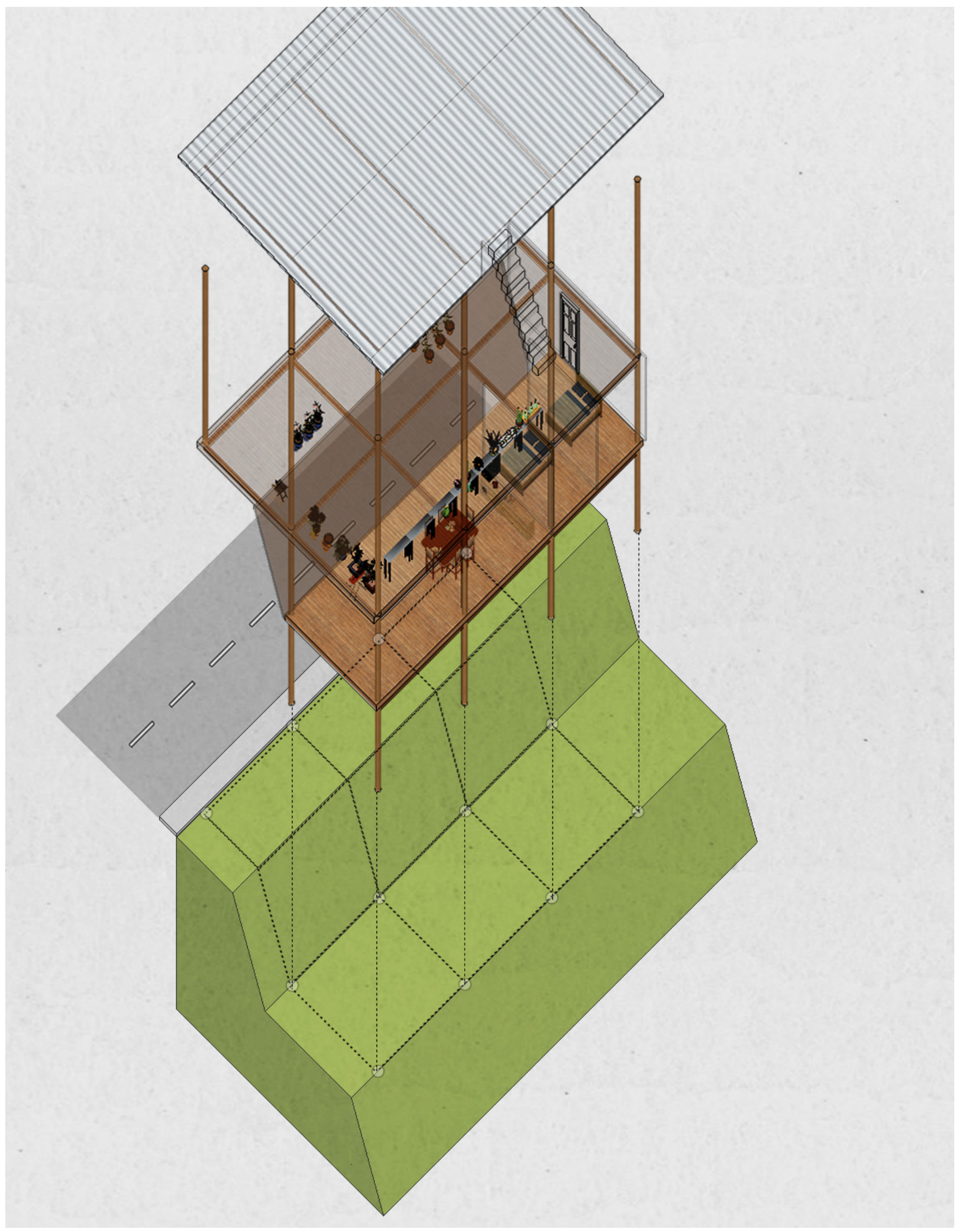

Figure 4: House in Puriscal. 
It could be argued that this case constitutes a different theme altogether, as the furthest extent of informality tends to dissolve into other more popular contemporary subjects such as illegal occupations or that it could shift from a legal definition of informality to physical informality as a more evident way to approach it, however it is in its direct friction with formality where the interest lies, by being adjacent to an agent of formalization (a highway) and by housing formal activities such as many kinds of transactions.

\section{LEARNINGS - APPLICABILITY}

Many of the above findings could be seen as lessons that can be applied directly to architectural and pedagogical projects alike but would be more fruitful to look for systematic ways to include them into practice in general. The following are some of these possible subjects.

Mediated knowledge vs. firsthand knowledge.

Technology's generative role is the most important one in the history of architecture but it can also create a great deal of detachment from the real circumstances of the world. Oftentimes projects start with an oversimplified version of reality caused by extreme dependence on technology that substitutes in-person knowledge. This is often followed by a response weakened by conformity to norms of representation.

Doing 1:1 vs. representing

The phrase "all architects do is representation" would probably be true were it not for hands-on onsite work that involves testing rather than correcting, exerting action on a site as a direct response to its conditions and uderstanding the consequences in real time. In-between experiences like Carlo Scarpa's drawings as a way to record and understand intense, rapidly changing realities like that of construction and to act accordingly are necessary references. Physical models, installations or mock-ups are an intermediary state between representation and the experience of inhabitation that are less likely to be delegated than construction itself.

Repetition and creativity

Finding new results by doing the same repeatedly. Opportunity for creativity manifests either by means of self-imposed constraints in the form of precise instructions and the reaction to a context or by documenting small accumulative evidences of evolution in a repetitive process.

Controlled improvisation

Allowing for room for the unexpected or the accidental within a predefined framework during construction. Another possibility is to define of participation for other actors outside the confines of the discipline.

Relieving the pressure for finished products

The conciliation of institutional requirements of all kinds with the acceptance that architects create the instructions for products that are not static. Understanding the submission of a project as a very precise moment in a much longer line of events, many of which fall outside of their control can bring attention back to the discipline as fulfilling rather than compensatory.

\section{ENDNOTES}

1. Allen, Stan. Practice: Architecture Technique + Representation, pg. 19. Routledge, NY.

2. Fernandez, Andrés (San José,1967). Architect, Historian, Researcher and Chronicler. Writer of several books and member of editorial boards in Costa Rica. Fernandez is also a professor of History of Architecture at Veritas University, San José.

3. Lefebvre, Henri. La producción del espacio. Capitan Swing, Madrid. 